\title{
AN EMOTION-BASED VIEW OF ACQUISITION INTEGRATION CAPABILITY
}

\begin{abstract}
We propose an emotion-based view of acquisition integration capability by developing an interfirm model that focuses on dealing constructively with emotions during various organizational identification processes following mergers and acquisitions. The model describes diverse types of organizational actions that elicit or express emotions--called emotional dynamics--that facilitate stabilization, destabilization, and re-identification of acquired employees’ organizational identity. Emotional dynamics that elicit emotions among acquired employees or express acquirer's emotions toward acquired employees constitute what we call emotional pairing. This emotion-based view of integration capability complements extant process research that has emphasized cognition and structure.
\end{abstract}

Key words: Acquisition Integration; Emotional Capability; Capabilities 


\section{AN EMOTION-BASED VIEW OF ACQUISITION INTEGRATION CAPABILITY}

Over the last decades, research on post-merger and acquisition (M\&A) integration has proliferated and includes processes such as forming ties across former firm boundaries, meshing cultures or organizational identities, and fostering trust and commitment among integrating firms (e.g., Larsson \& Lubatkin, 2001). Notably, researchers have focused on integration capability, that is, a set of organizational practices to manage the post-M\&A integration process, which involve topics such as the structural qualities of integration, including the role of inter-organizational structures to facilitate communication across former firm boundaries, retention of acquired executives and provision of autonomy of the acquired unit to preserve its capabilities, and perceptual or cognitive elements of integrating two firms, such as perceived procedural fairness in postacquisition integration, codification of organizational learning (e.g., Schweiger \& DeNisi, 1991; Zollo \& Singh, 2004). A leading stream in this work has focused on cognitive shifts in acquired organization members’ organizational identities (Clark, Gioia, Ketchen, \& Thomas, 2010; Hogg \& Terry, 2000), that is, an inevitable change in "what members believe to be central, enduring, and distinctive about their organization,” addressing employees’ existential question “Who are we as an organization?” (Albert \& Whetten, 1985).

These research efforts have given us an insightful body of knowledge about the structural and cognitive aspects of post M\&A integration processes. However, the emotional dimension-that is, the ways in which firms’ decision-makers deal constructively with acquired employees’ emotions that arise as a result of the integration process--has remained largely under-investigated in research on integration capability. This under-examination seems intriguing because many scholars have noted that M\&As can evoke strong emotions and the latter could influence integration outcomes (Kusstatscher \& Cooper, 2005). 
Emotions are important to consider because psychological research has found that they can have important bearing both on individual attitudes, behaviors and perceptions, and on collective organizational behavior (e.g., Weiss \& Cropanzano, 1996). At the individual level, anger and fear, for example, can consume precious psychological resources, which can lead to cynicism, disengagement, and turnover among employees (e.g., Kusstatscher \& Cooper, 2005). At the collective level, shared emotions can energize large groups of employees to support or sabotage attempted changes inherent in post-acquisition integration activities (Huy, 2002).

We start our emotion-based theorizing by drawing on an emerging stream of research that explores emotion in strategic change (Huy, 1999; Sanchez-Burks \& Huy, 2009). Scholars construe "emotion" as a multifaceted process in which people cognitively appraise a stimulus, interpret the meaning of the stimulus, and experience a feeling state and physiological changes as a reaction (e.g., Elfenbein, 2007). Because of these causes and effects, emotions can play a central role in influencing employees' support or opposition of strategic change (Dutton, Worline, Frost, \& Lilius, 2006; Huy, 1999). In particular, in Huy’s theorizing on emotional capability as an organizational competence, emotional dynamics refer to organizational behavior, routines, or practices that perceive or manage employee emotions to facilitate their receptivity, mobilization and learning during radical change (Huy, 1999).

However, how emotional dynamics influence acquisition integration capability has remained largely under-examined. Dealing constructively with employees’ emotions can be a challenging task for managers of many firms because it might require perceiving and managing employees' diverse and evolving emotions across dissolving organizational boundaries. Theorizing about emotional dynamics in integration capability, therefore, can help address an important gap in the acquisition integration literature. 
A focus on emotional dynamics holds promise for complementing the more traditional strategic perspectives on M\&As, which have had difficulty explaining acquisition outcomes (e.g., King, Dalton, Daily, \& Covin, 2004). A focus on perceiving and managing emotions related to integration capability — and that focus on the emotional supporting roles of both the acquirer and acquired firm—can provide new insights into the challenges of acquisition implementation itself. To do this, we will draw mainly on three literatures: acquisition integration, organizational identification, and emotional capability.

\section{EMOTIONS AND ORGANIZATIONAL IDENTIFICATION PROCESSES}

Scholars have highlighted the impact M\&As have on acquired firms’ organizational identities (Hogg \& Terry, 2000), that is, a change in what members believe to be central, enduring, and distinctive about their organization (Albert \& Whetten, 1985). Social identity theory (e.g., Tajfel \& Turner, 1979) suggests that beyond a personal self, people have a "social self,” which they derive primarily from their group memberships. Individuals manage their sense of social self, or social identity, by assigning themselves and others into various social groups such as the organization they work for (e.g., Hogg \& Terry, 2000). Therefore, acquired managers’ social self is often linked to their former firm. Over time, people identify with—that is, develop a sense of oneness with—the firm they work for and define themselves in terms of their organization's attributes (e.g., Dutton, Dukerich, \& Harquail, 1994; Fiol, 2002). Because M\&As often entail changes to organizational identity, identification processes can emerge and influence employees' responses to integration efforts (Clark et al., 2010). Indeed, early M\&A scholars noted the persistence of "us" versus "them" conflicts when employees have difficulty relinquishing their old identities, and observed that clashes of cultures or social identities are an important cause of acquisition failure. 
In the organizational literature, identification can be construed as both a state of being identified with an entity and as a process of becoming identified with another entity (Kreiner, Hollensbe, \& Sheep, 2006). When identification is treated as a state, individual and organizational identities align, so that individuals feel a sense of "oneness" with their organization (Ashforth \& Mael, 1989). Identification as a process is portrayed as a reciprocal interaction between the individual and the target of identification that occurs as people discover affinity with the target or seek to alter their identity to align with that of the target (Pratt, 2000). Identification as a process is social, interactive, and ongoing, and thus can potentially be altered by activities that create employees' affinity or sense of “oneness” with a new firm (Gutierrez, Howard-Grenville, \& Scully, 2010).

The social identity view on M\&As has tended to focus on cognitive dynamics involved in acquisition integration. This cognitive view posits that employees prefer to perceive a continuation of their pre-acquisition organizational identity in post-acquisition phases (e.g., Rousseau, 1998; Ullrich, Wieseke, \& van Dick, 2005). This research stream links the dynamics of acquisition integration to various identification processes including maintaining separate organizational identities, de-identifying with pre-M\&A organizations, re-identifying with the acquirer, or defining a new organizational identity (Clark et al., 2010; Terry, Carey, \& Callan, 2001; Vaara, 2000).

We argue that these cognition-based identification processes can also generate important emotional consequences. Empirical studies that draw on cognitive appraisal theory of emotions have shown that emotions are elicited when people appraise events, real or imagined, as having potential consequences that are important to self or to entities they strongly identify with (e.g., Lerner \& Keltner, 2001). Because identification processes shape our sense of being and belonging — what is most valuable to us (Dutton et al., 1994) — they can trigger strong emotions that in- 
fluence subsequent thinking and behavior (Elfenbein, 2007). Moreover, the emotions that are elicited during M\&A integration tend to be of an enduring nature (e.g., acquired employees feeling anger toward acquirer executives who display dismissive behaviors toward their company's products), as opposed to less consequential, episodic emotions that could be forgotten quickly (e.g., being upset by a computer malfunction that was fixed shortly later).

The fact that identification processes elicit strong emotions during M\&A integration processes has long been observed by researchers. However, much research that mentions the emotional effects of M\&As has tended to remain largely descriptive, focus on their harmful effects, and offer insufficient theorizing on how organizations can deal constructively with employee emotions to enhance integration success. Losing a sense of identity elicits repressed feelings of attachment or belongingness and can evoke feelings of apathy, anxiety, frustration, and insecurity among employees from both the acquirer and acquired firm. Empson (2001) also stressed that employees experienced fear of contamination by the image of their acquisition partner.

Kusstatscher and Cooper (2005) identified a range of emotions that comprise a merger syndrome, such as feelings of anxiety, insecurity, anger, frustration, shame and pride.

Moreover, emotions are also mentioned, often peripherally, in discussions of sociocultural integration, resistance to cultural change, or culture clashes that are underpinned by identification processes (e.g., Buono \& Bowditch, 1989). Chatterjee and his colleagues (1992), for example, noted that “[d]issimilar cultures can produce 'feelings of hostility' and 'significant discomfort'” (321). These cultural differences have been linked to threats to organizational identity that amplify employees' emotional attachment to their former firms. Vaara (2000) described that emotions influence identification processes - negative emotions about the other company produced cultural alienation, whereas positive emotions led to cultural attachment following 
M\&As. Other scholars have linked emotions to diverse modes of acculturation that cause acculturative stress among acquired employees (e.g., Nahavandi \& Malekzadeh, 1988) or to cultural conflicts between firms' top management teams (e.g., Datta, 1991). Some scholars began to note that dealing with emotions may help integration performance, such that employees who have a strong socio-emotional orientation are less likely to reduce commitment to the post-acquisition organization (Gaertner, Bachman, Dovidio, \& Banker, 2001). Collectively, this body of works has often reported the negative emotional consequences of M\&As and suggest that dealing with the emotional nature of identification processes represents an important yet underexplored dimension of integration capability.

Recent research suggests that dealing constructively with emotions facilitates adaptation in radical change processes by emotionally committing employees (Huy, 2002). This work concentrates on the role of emotional dynamics in the form of organizational actions that evoke or express emotions during disruptive and emotionally intense change situations. We extend this work by developing an inter-organizational model of post-acquisition integration that focuses on dealing constructively with patterns of emotions experienced by acquired employees via organizational actions linked to perceiving and managing emotions, called emotional dynamics.

As a prelude to our theorizing we make two restrictive assumptions. Researchers have described a variety of approaches to implement acquisitions (e.g., Cording, Christmann, \& King, 2008; Haspeslagh \& Jemison, 1991; Nahavandi \& Malekzadeh, 1988; Ranft \& Lord, 2002). For the sake of parsimonious theorizing, we take the simplifying assumption that acquirers either provide autonomy to the acquired firm or they integrate it into their own organizations. This distinction is helpful because it allows us to emphasize contrasting effects on power struggles, socio-cultural integration, boundary management, and other factors inherent to post-acquisition in- 
tegration. We assume, moreover, that these two approaches entail distinct aspired organizational identity outcomes. When decision-makers of an acquirer choose to provide autonomy to the acquired firm, they likely harbor an underlying aspiration to stabilize the acquired employees’ organizational identity to their former firm in order to preserve acquired capabilities (Haspeslagh \& Jemison, 1991; Ranft \& Lord, 2002). In contrast, when decision-makers choose to integrate an acquired firm, they likely aspire to abandon the acquired employees' organizational identity to their former firm, and attach it to the acquirer's organizational identity. We will draw on this distinction to consider how each approach can influence the effectiveness of organizational actions to deal with emotions. Table 1 summarizes key characteristics of the two approaches that are relevant to our theorizing. It is important to note that these integration approaches represent ideal types, that other approaches exist and can overlap one another in practice. We will come back to this point in our later discussion.

\section{Insert Table 1 and 2 about here}

We also focus our theorizing on the acquired firm's identity outcomes. Each integration approach elicits different patterns of emotions (summarized in Table 2) with distinct identification outcomes for employees of the acquired firm. We reckon that the organizational identity of the acquirer's employees may be impacted as well. Particularly when acquisitions involve large firms of equal size, the consequences for acquirers and acquired firms are not always clearly distinguishable (Ellis \& Lamont, 2004). We posit, however, that this scenario likely involves emotional dynamics and identification processes that differ more in degree than in kind to the ones we propose next. We will elaborate on this point later in the discussion section.

Below, we develop an emotion-based view of acquisition integration capability by describing an inter-organizational model that focuses on dealing with acquired employees' emo- 
tions — arising from various identification processes—-that relate to two distinct approaches: maintain considerable autonomy for the acquired firm or integrate the latter in the acquirer. We also focus on both the acquirer and acquired firm supporting each other in managing acquired employees' emotions related to identification processes—a concept we call emotional pairing.

\section{EMOTIONAL DYNAMICS OF AUTONOMY PROVISION}

Autonomy provision is typically used when the key acquisition motive is to capture an acquired firm's valuable capabilities, which the acquirer does not have. Acquirers may take this approach when they want to enter a new product or geographic market (Bower, 2001). To achieve this strategic goal, acquirers strive to maintain acquired employees' commitment to exploiting or further developing acquired capabilities so that the acquirer can gradually learn about opportunities in the new product-market (Haspeslagh \& Jemison, 1991).

Acquirers thus use autonomy provision to limit harmful interference in the use of acquired capabilities. Inter-organizational interactions occur mainly at the top management level, while interactions between middle management of both firms are less actively promoted (Haspeslagh \& Jemison, 1991). This approach favors firm boundary protection and stresses that employees of both firms tolerate continuing differences within the new "combined" organization. For example, the Air France-KLM merger was purposefully branded as a "combination” to underline continuation of the two distinct organizational identities. To facilitate preservation of acquired capabilities, it is critical for the acquirer to retain the acquired firm's top management team and to give that team considerable independence (e.g., Ranft \& Lord, 2002). This includes letting the acquired firm keep its culture and stabilizing its original organizational identity that fosters its employees' continued commitment to exploit and develop those capabilities that are valued by the acquirer (Napier, 1988). 
Because this approach typically involves inter-firm interactions at the top team level, employees of the acquiring and acquired firm should be little affected by the acquisition itself. But this hands-off approach can still evoke harmful emotions among employees of the acquired firm. They may still fear that the acquirer will make a controlling attempt in the future, and that current firm boundaries will break down (cf. Empson, 2001). This anticipated emotion can lead to heightened vigilance among acquired employees who are suspicious of acquirers' motives. Such vigilance can be harmful because it constrains knowledge-sharing with the acquirer, thereby reducing the acquirer's ability to learn from the acquired firm, and making it more difficult to identify and develop emerging opportunities in the new markets (cf. Szulanski, 1996).

It follows that attention to emotions should be focused primarily on the acquired firm's top management both because most critical interactions between the two firms occur at this level, and because decision-makers of the acquirer are often ignorant of subtle, tacit, cultural and people-related factors that make it possible to deal constructively with acquired employees' emotions (cf. Graebner, 2004). In addition, too much interference in the lower managerial ranks of an acquired firm can threaten the acquired top team's desire for autonomy and provoke defensiveness. It seems thus desirable to let acquired top managers continue running their own operations, including managing the emotions of their subordinates, so that the acquired firm's influential employees remain committed to exploiting and developing the acquired firm's capabilities.

Researchers have suggested that in order to maintain a sense of status among key acquired employees, it is important to let the acquired firm retain considerable autonomy (e.g., Hambrick \& Cannella, 1993). This research stream assumes that allowing autonomy alone will suffice to stabilize the acquired unit's organizational identity and preserve acquired firms' valuable capabilities. Yet, we contend that permitting autonomy in and of itself is not enough; firms 
must also pay attention to the fact that acquired top managers' emotions will evolve over time.

\section{Emotional dynamic of pride and comfort (reassurance) elicited among acquired}

employees. Paradoxically, although allowing for autonomy may give acquired top managers a perception of retained status (Hambrick \& Cannella, 1993), prolonged autonomy could eventually arouse harmful emotions when acquired top managers interpret non-interference as neglect, abandonment, or exclusion. They may come to fear that their autonomy is transient, perhaps just an acquirer's ploy to buy time and take advantage of the acquired firm's capabilities in some manipulative way (Empson, 2001) or divest their unit to an unknown buyer (Bergh, 1997). In short, when autonomy provision is perceived as taken to its extreme, and acquired top managers are left without regular meaningful interactions with their acquirer’s top managers, they more likely feel threatened due to limited knowledge about the acquirer’s strategic plans. Furthermore, they may even come to feel resentful about the acquirer ignoring them (cf. Meyer \& Altenborg, 2007).

We thus argue that providing autonomy will only ensure stabilization of the acquired firm's organizational identity if it is complemented with the emotional dynamic of reassurance, which elicits emotional states of pride and comfort. First, this emotional dynamic involves organizational actions showing acquirer’s decision makers valuing their acquired counterparts for their distinctive capabilities, thus eliciting their pride. Pride is pleasure aroused when people believe that a positive outcome can be attributed to one's own specific actions (Lewis, 2000). Pride serves a social communicative function inasmuch as this emotion helps acquired top management express the worth of their past achievement and their expectation for the acquirer's top managers to adjust their opinions upwards in accordance with these achievements. As Albert (1984) noted, a proposed change can be resisted not only because the future is unknown and 
feared, but because the past is underappreciated. When acquired top managers feel appreciated and proud, the positive emotions facilitate exploration of new ideas and cooperation with the acquirer top team, reducing their initial mistrust of the acquirer's motives.

A second emotional state that is elicited by the emotional dynamic of reassurance is comfort. As noted, acquired top managers may remain highly vigilant and distrustful of the acquirer's hidden motives to exploit them. It is therefore important to elicit a quiescent emotional state of comfort among acquired top managers in regard to their continued leadership role in nurturing the acquired firm's valuable capabilities. Comfort is an emotional state of low arousal and positive valence. Individuals likely experience comfort when the environment is perceived as being stable, benign, and presenting no potential harm (cf. Lazarus, 1991). Emotional states of comfort at work can be construed as the emotional dimension of psychological safety at work, which involves cognitive, affective, and behavioral elements (Edmondson, 1999). Psychological safety refers to "feeling able to show and employ one's self without fear of negative consequences to self-image, status, or career” (Kahn, 1990: 708), which in turn reduces fear about harmful consequences for one's self.

People are likely to feel comfort when their work interactions reflect mutual respect for their own and others' competences. Comfort allows acquired executives to continue to focus on the exploitation of their firm's existing capabilities, free from extreme worry about risks and defensive behaviors (cf. Edmondson, 1999). Enacting the emotional dynamic of reassurance to elicit comfort in regard to managing the acquired firm quasi-autonomously can take the form of regular, egalitarian discussions of past achievements and future joint strategic directions among top managers of both firms. Other actions to promote reassurance could be regular displays of respect by acquirer top managers as a way of recognizing the valuable competences and contri- 
butions of their acquired colleagues, and eliciting pride.

Although these reassuring actions—eliciting pride and comfort—are directed mainly at acquired top managers, they can have important consequences for lower-level employees’ perception of stabilized organizational identity. Acquired top managers' emotional states can diffuse among their subordinates through a variety of social-psychological mechanisms. Leaders' emotions can exert a powerful contagious effect on followers' emotional states and their ways of thinking and behaving (Sy, Côté, \& Saavedra, 2005). This process occurs through both cognitive and emotional channels. When top managers, who are experiencing pride and comfort, communicate integration-related issues with their subordinates, they likely communicate their emotions that convey their appraisal of stabilized organizational identity. These interactions help lower-level employees develop similar interpretations of M\&A-related events and actions, and experience similar emotions (cf. Hatfield, Cacioppo, \& Rapson, 1994). Moreover, emotions tend to spread from one organization member to another, albeit often unconsciously. As a result of this emotional diffusion conveying stabilized organizational identity--eliciting acquired employees' pride about valuable capabilities and comfort about respectful relationships with the acquirer--acquired employees can focus their energy on exploiting and developing their firm's capabilities (Edmondson, 1999).

Proposition 1a: The emotional dynamic of pride and comfort (reassurance) elicited among acquired top managers moderates the relationship between autonomy provision and stability of the acquired firm's organizational identity such that with (without) reassurance autonomy provision increases (reduces) the likelihood of organization identity stabilization.

Emotional dynamic of hubris-containment to be expressed by the acquirer firm. In addition, to enhance the effectiveness of the emotional dynamic of reassurance directed at the 
acquired top managers, the acquirer can increase the credibility of such actions by displaying hubris-containment. Hubris refers to extreme display of pride about one’s own attributes (Hayward \& Hambrick, 1997). To the extent that top managers of the acquired firm perceive the acquirer's top team to display “victorious" behaviors that reflect arrogance and excessive pride (i.e. hubris) about the acquirer's superior power, resources, or capabilities, acquired top managers are likely to conclude that acts of emotional dynamic of reassurance directed at them are not genuine and are designed to make them less vigilant so that the acquirer can take advantage of the acquired firm's capabilities.

For this reason, for the emotional dynamic of reassurance to help stabilize the acquired top team's organizational identity, the acquirer top team has to be careful in not displaying what could be perceived as hubris. The acquirer's top team can, for example, avoid making comparison statements that risk creating feelings of shame or embarrassment for the acquired executives (e.g., accounts of underperformance or inferiority in capabilities, resources, or power), lest these emotions generate automatic defensive mechanisms to restore the acquired executives' selfesteem and the identity and image of their organization (Brown, 1997). By displaying an attitude of modesty and equality when dealing with the acquired top executives, acquirer top executives reinforce the perceived authenticity of acts of reassurance and enhance the likelihood of stabilizing the acquired top team's organizational identity.

Proposition 1b: The emotional dynamic of hubris-containment expressed by acquirer's top managers moderates the relationship between autonomy provision and stability of the acquired firm's organizational identity such that with (without) hubris-containment autonomy provision increases (reduces) the likelihood of organization identity stabilization. 
Emotional pairing. Enacting the emotional dynamics of reassurance together with hubris-containment to convey the authenticity of the dynamic of reassurance constitute what we call emotional pairing. More formally, emotional pairing refers to a set of associated emotional dynamics that seek to regulate emotions (i.e. elicit new emotions, alter existing emotions, or avoid expressing certain emotions) in the receiver as well as in the sender. In this case, the acquirer top team (sender) seeks to elicit new emotions (pride and comfort) in the acquired top team (receiver) by enacting the emotional dynamic of reassurance. The latter is associated with the emotional dynamic of hubris-containment, in which the sender (acquirer top team) regulate its own emotions (avoid expressing excessive pride or hubris) in order to convey the authenticity of the dynamic of reassurance and enhances organization identity stabilization among the acquired top team. By including both sender and receiver in two distinct yet interrelated emotional dynamics, emotional pairing represents a novel concept to the emotional capability literature. Below, we show more manifestations of emotional pairing between the acquirer and acquired firm to show the inter-organizational nature of our theoretical model (depicted in Figure 1).

\section{Insert Figure 1 about here}

\section{EMOTIONAL DYNAMICS OF ACQUISITION INTEGRATION}

Acquirers integrate acquired firms to strengthen their own market position or to become more cost-efficient. Acquired firms are then required to adapt to, and adopt, many of the acquirers’ policies and practices (Napier, 1988). Accomplishing this often entails a fast pace of change, bringing acquired employees (including top managers) under the full control of the acquirer or letting them go. Power imbalance is prevalent as acquirers' top managers seek to exert strong control over acquired firms (Haspeslagh \& Jemison, 1991).

When acquirers’ decision makers aspire to integrate an acquired firm, this integration 
ideally involves attaching acquired employees’ organizational identity to that of the acquirer. Such integration challenges the acquired employees' status quo and destabilizes their organizational identity. These events can elicit strong emotions among acquired employees and should be managed constructively with the help of emotional dynamics that foster destabilization of the acquired firm's organizational identity; contains the harmful effects of such destabilization on acquired employees; and help move acquired employees from destabilization toward reidentification with the new firm.

\section{Emotional Dynamics Fostering Destabilization of the Acquired Firm's Identity}

Thus far, we have discussed how certain emotional dynamics can help stabilize acquired employees' identification with their firm so that beneficial exploitation of the acquired capabilities can occur. However, despite the acquirer's best efforts, the acquired firm’s organizational identity could remain fundamentally incongruous with that of the acquirer. For example, Meyer (2006) describes how a merger among four Scandinavian partners that allowed considerable autonomy to separate units led to contradictory strategic intents and organizational identities, which eventually led to implementation failure. A conflicting organizational identity of the acquired firm risks diverting the acquirer's fundamental strategic motives. One way to solve this conundrum would be to divest the acquired firm. The majority of unrelated acquisitions are actually divested, which often result in major financial losses for both the acquirer and acquired firm (Bergh, 1997).

Another approach would be to try bringing the acquired firm into the fold of the acquirer by making acquired employees identify strongly with the acquirer. In some fortunate cases, acquired employees can identify simultaneously with their acquired firm and the acquirer (e.g., van Knippenberg \& van Leeuwen, 2001), or may accept a super-ordinate post-merger identity that is 
inclusive of multiple organizational identities (e.g., Gaertner et al., 2001). But there are situations in which a high level of integration requires acquired employees to de-identify with their former organizational identity and re-identify with the new one. Because this transition can create considerable emotional hardship for these employees, sensitive application of emotional dynamics to facilitate this transition is important.

\section{Emotional dynamic of dissatisfaction enacted among acquired employees. Re-} identification often starts with a shift from organizational identity stabilization to temporary destabilization: acquired employees go through a process of de-identification whereby they experience psychological abandonment of salient aspects of their former organizational identity (Brewer \& Miller, 1984). By its very nature, this shift involves at least some degree of deidentification for employees (Fiol, 2002). This likely represents one of the most sensitive steps in an integration process. Destabilization of organizational identity creates loss of meaning and can be extremely painful. However, without destabilization acquired employees unlikely abandon their cherished organizational identity. Destabilization is often necessary for people to become open to new opportunities (Fiol, 2002).

People do not typically de-identify from entities they value. Therefore, to the extent that acquired employees can be helped to see a broader perspective and other firms' valuable attributes that have not been made salient to them, they can then engage in a process of sensemaking and sensegiving in which they can discuss their evolving levels of identifications with their former organizational identity (Gioia \& Chittipeddi, 1991). Empirical research on de-identification processes have suggested the emotional state of dissatisfaction with the current performance of the organization as an important driver for collective sensemaking and major change to certain elements of organizational identity (Gutierrez et al., 2010). In fact, emotion theorists have identi- 
fied dissatisfaction as a distinct "distress" emotion, which is evoked when an event is perceived as unpleasant or obstructive to people’s goals or needs (e.g., Ortony, Clore, \& Collins, 1988). Dissatisfied people tend to feel unfulfilled, and this can trigger information-seeking about the causes of the affective event. Dissatisfaction is closely associated with anger, and thereby, involves an action tendency to address the problematic situation (Bougie, Pieters, \& Zeelenberg, 2003). As such, feelings of dissatisfaction help individuals to question the status quo, to distance themselves from what they have been used to, and to seek out new ways.

An acquirer may therefore stimulate influential employees of the acquired firm to feel strongly dissatisfied about certain core elements of their former organizational identity to stimulate the destabilization process. Organizational actions that elicit dissatisfaction include convincing acquired employees to see that the goals they sought to achieve, the values they held, or the way work was done in the past are no longer optimal to the long-term welfare of their firm. Acquirers can evoke dissatisfaction by facilitating the rejection of existing beliefs and initiating a reframing of problems (Kaufmann \& Vosburg, 1997). For example, decision-makers can attract acquired influential members' attention to certain important problem areas in their former firm that could be potentially addressed with the acquirer's help. These influential employees can in turn convince their colleagues to share their changing perspectives. Dissatisfaction about outcomes that are perceived as worse than people's aspirations can foster receptivity to change and destabilize some elements of their organizational identity (Gutierrez et al., 2010).

Proposition 2a: The more activities related to the emotional dynamic of dissatisfaction are enacted, the more likely acquired employees shift from organization identity stabilization to destabilization.

Destabilization of organizational identity, however, risks arousing acquired employees’ 
emotions that ultimately harm the preservation of acquired capabilities and even damage acquirers' own capabilities, and can produce so-called merger syndromes with destructive outcomes (Marks \& Mirvis, 1985). The higher the demand for integration, the more destabilization is likely to occur. The acquirer firm should thus seek to reduce the harmful effects of destabilization on acquired employees by expressing emotions that convey that they empathize with acquired employees’ pain.

Emotional dynamic of empathy to be expressed by the acquirer managers. To the extent that acquired employees identify strongly with their old firm, destabilization through abrupt organizational boundary dissolution, rapid restructuring, and adoption of acquirer's practices likely elicit intense negative emotions. These include fear of undesirable changes to work and private lives, anger about the acquirer's aggressive actions, shame and sadness associated with loss of identity and status (e.g., Kusstatscher \& Cooper, 2005). For example, Ullrich and colleagues (2005) studied an acquired firm where the removal of a non-core business activity bearing high cultural meanings caused its employees to experience intense feelings of loss. Integration of an acquired firm into the acquirer's organizational structure destabilized employees' identification with their former firm. Acquired employees' negative emotions risk causing not only decline in their morale and task effectiveness (Sy et al., 2005), in extreme cases it also could produce widespread organizational sabotage (Buono \& Bowditch, 1989). Clearly, these negative emotions can hurt the success of integration. While destabilization may be required as a first step toward re-identification (Empson, 2004; Fiol, 2002), destabilization left on its own unlikely fosters constructive acceptance of a new organizational identity.

In contrast to autonomy provision, integration requires acquirers to exert high control over the acquired firm's operations. Some acquired top managers might be receptive to convert- 
ing the emotional attachment toward their old firm to the newly combined company. However, others may find this conversion emotionally difficult because they have psychologically invested in their former company for a long time. Thus, it is common that acquired top managers are replaced or subordinated to the power of the acquirer to achieve efficiency and exploit the acquirer’s own capabilities (Haspeslagh \& Jemison, 1991). As acquired top managers lose power or leave their firm, it becomes critical for the acquirer's top managers to build good relationships with influential middle managers of the acquired firm and co-opt them to realize important M\&A objectives and contain the harmful effects of destabilization (e.g., Huy, 2002). Acquired middle managers likely play a critical role among acquired employees because they can influence their subordinates' emotions—-being physically closer to their subordinates and knowing the latter's task and social-emotional needs— and thus are the ones who can implement social-emotional remedial actions more effectively than top managers (cf. Huy, 2002). Acquired middle managers who stay with their firm, moreover, could experience emotions of guilt and even depression, which have been associated with so-called survival sickness that paralyzes any form of identification with an acquirer. To deal with these harmful effects, we suggest the emotional dynamic of empathy to be expressed by acquirer managers toward acquired employees.

Following Batson (1990), we construe empathy in a broad sense to include feelings of sympathy and concern for the other. The acquirer can demonstrate empathy by requiring and training its top and middle managers who act on its behalf, when dealing with acquired employees, to convey that acquirer's managers: (a) can feel what other acquired employees feel if they were put in the same situation of organizational identity destabilization, (b) put themselves in the place of acquired employees when making important decisions that affect acquired employees, and (c) are motivated to take actions that show they pay attention to acquired employees' suffer- 
ings and are motivated to reduce their pain (e.g., Dutton et al., 2006).

Illustrative empathetic actions include treating departing acquired top managers with respect and compassion. Acquirer's top managers can, for example, extol the contributions of departing acquired top managers and employees, provide psychological and job placement counseling, and offer assistance to family members who experience disruptions due to job relocation. Many actions that have been described in the procedural and interpersonal justice literature (e.g., Ellis, Reus, \& Lamont, 2009) are illustrative of the emotional dynamic of empathy. This literature has found that when employees feel they have been treated with compassion and dignity, in emotion-laden events such as lay offs, they are less likely to experience antagonistic emotions such as anger, even when resulting decisions have negative outcomes (e.g., Kim \& Mauborgne, 1998).

Furthermore, when acquired middle managers observe that their former top managers are treated in an empathetic way, they likely develop an enhanced appreciation of the acquirer's organizational identity. These middle managers likely infer that they would be treated in a similar way in the new organization and become more accepting of the acquirer as their new employer. In other words, the emotional dynamic of empathy not only helps reduce destructive responses by acquired top managers and their subordinates but also can signal to “surviving” middle managers how they will be treated, thus reducing the harmful effects of their survivor sickness.

Proposition 2b: The emotional dynamic of empathy enacted by an acquirer's managers moderates the relationship between level of integration and destabilization of the acquired firm's organizational identity such that with (without) empathy, integration reduces (increases) the harmful effects of organizational identity destabilization on acquired employees.

In sum, if the emotional dynamic of dissatisfaction elicited among acquired employees is 
supported by the dynamic of empathy that is expressed by acquirer's managers, acquired employees likely perceive that the acquirer firm, via its representative leaders, understand their opinions and feelings and care about their well-being. They likely respond with non-defensive, constructive responses. In other words, the effectiveness of dissatisfaction with acquired employees on integration outcomes is supported by empathy expressed by managers of the acquirer. Together, the emotional dynamic of dissatisfaction elicited among acquired employees and the emotional dynamic of empathy to be expressed by acquirer's management constitute another manifestation of emotional pairing at the inter-firm level.

\section{Emotional Dynamics Fostering Re-identification with a New Organizational Identity}

From a social identity perspective, successful integration of an acquired firm ultimately entails a move from organizational identity destabilization to re-identification - i.e., shifting the acquired employees' object of identification from the acquired firm to the acquirer. Acquired employees reduce their emotional attachment to their old firm and redirect it to the new firm. This re-identification requires attachment to the acquirer's organizational identity, which we propose can be facilitated by the emotional dynamics of hope and love.

Emotional dynamic of hope elicited among acquired employees. While previous emotional dynamics related to comfort and pride, hubris-containment, dissatisfaction, and empathy help acquired employees make sense of their former organizational identity, past performances, or current relationships with the acquirer, hope captures the anticipated, future emotional quality of acquired employees' relationship with the new organization. Acquired employees likely accept painful losses associated with organizational identity destabilization and re-identify with the new firm faster if they believe that their losses will ultimately lead to a better personal future inside the new firm — that is, they experience hope. 
An acquirer's managers can elicit hope among acquired employees about a better future in their new firm by performing various actions such as: involving acquired employees in the codefinition of important organizational goals for the newly combined firm; making sure that these employees have an influential voice in key aspects of the acquirer's decision making; frequent and energizing dialogue among acquirer top managers and groups of acquired middle managers, who, in turn, will share their perceptions and feelings about the acquirer with their subordinate employees; encourage acquired employees to take initiatives and innovate (Mishra \& Spreitzer, 1998); granting them adequate resources to help them achieve their aspirations with their new firm; promote and reward acquired employees who bring value to the new firm; create small wins to rekindle optimism and self-confidence.

Hope is an emotional state that is elicited by appraisal of future positive prospects for self (Ortony et al., 1988). Hope could also be elicited by perceived relational quality, that is, when employees service one another and bind themselves as members of a community. Hope is elicited when acquired employees perceive a future that is open-ended and becoming, in which they can toy with generative possibilities, improvise, and co-create a coherent image of the future. Hope arises when people, faced with an uncertain post-merger integration, perceive agency in improving their situation ("We can do this") and goal-directed pathways ("We can find alternative paths if our current way to achieve our goals is blocked”) (Snyder, Rand, \& Sigmon, 2002). Feeling states associated with hope include positive affect, such as joy about anticipated improvement and feeling more energized by goals. Action tendencies include intentionality to act (“We will do this”), not merely the perceived ability to act (“can”) involved in self-efficacy (Bandura, 1997). In contrast, a lack of hope can lead to passive avoidance and disengaged coping behavior (Snyder et al., 2002) that harm the re-identification process. 
Proposition 3a: The more activities related to the emotional dynamic of hope are enacted, the more likely acquired employees' shift from organization identity destabilization to re-identification to the new firm.

Emotional dynamic of love expressed by acquirer firm. Although the dynamic of hope can facilitate acquired employees' re-identification with the new firm, in that they feel that their future likely improves, acquired employees may still harbor a deep fear that they might be treated well but still as 'second-class-citizens' inside the new firm. The fear of ingroup and outgroup dynamics that would disadvantage acquired employees' full development in the new company may still exist and produce defensive behaviors that harm integration efforts (Marks \& Mirvis, 1985). For acquired employees to fully identify with the new firm, acquirer employees have to convey to acquired employees that they cherish and value them as equal and full members of their community. From an affective perspective, the associated emotions to be expressed involve affection and love toward acquired employees, thereby building emotional bonds.

In a business context, managers of the acquirer firm can express love to acquired employees by providing unconditionally to them the same organizational rights and privileges that current acquirer employees benefit. In particular, visible and rapid appointments of a number of acquired employees in senior positions in the new firm can bear a high symbolic value for the majority of acquired employees. Other illustrative love-expressing actions include: providing favorable access to many influential positions in the new firm; demonstrating that the organization cares about the long-term development and welfare of acquired employees and their significant others, such as job development, education, health concerns (including sports facilities), and medical, pension, and family benefits; providing resources to further causes that acquired employees cherish (e.g., protection of environment, charitable causes, work achievements). 
Scholars have described the identifying process as analogous to "falling in love," that is, to the extent that one's expectations are fulfilled and reciprocated, the initial attraction ripens into a deep and abiding attachment; this identification process is both cognitive and affective (Ashforth, 1998: 9). Members in a collectivity stay together because there are mutual benefits; and among the most important of these are the emotional bonds that develop over time in relation to self-identified and shared organizational characteristics. Individuals will be motivated to identify more strongly when their organization identities evoke positive affect, and to disengage if they produce negative affect (Harquail, 1998). Emotional bonds determine in part the work structure, and influence the organization's norms and standards (van Maanen \& Kunda, 1989). Emotional bonds also undergird organization identity by providing stable psychological structures to contain anxiety, a commonly shared emotion that serves as a signal for the avoidance of a dangerous situation. Love that is conveyed in emotional bonds elicits among acquired employees the critical experience of security and acceptance, which people seek since their birth (Winnicot, 1965). Acquired employees bond to an organizational identity that affirms their sense of identity and belonging (Bartunek, 1984). Emotional identification often translates into resilient loyalty to the organization (Huy, 1999). Together, expression of love and the shaping of emotional bonds among members of the acquirer and acquired firm help acquired employees feel that they are welcome as full-fledged 'family' members in the new organization, and this helps them move from an alienating state of destabilized organizational identity to a bonding state of reidentification with the acquirer firm.

Proposition 3b: The more acquirer managers enact activities that express love to the acquired employees, the more likely acquired employees will move from destabilization to re-identification to the new firm. 
In sum, if the emotional dynamic of hope is elicited among acquired employees is supported by the dynamic of love that is expressed by acquirer managers, acquired employees likely perceive that the acquirer firm (and its representative leaders) are genuinely motivated to improve their well-being inside the new firm and to integrate them as full members of their community. Acquired employees likely respond in a cooperative way. The beneficial effects of hope that is elicited among acquired employees in regard to re-identification and integration outcomes are further supported by the dynamic of love that is expressed by acquirer managers, creating emotional bonds between acquirer and acquired employees that solidify newly formed taskbased relationships. Together, the emotional dynamic of hope elicited among acquired employees and the emotional dynamic of love expressed by acquirer management constitute another manifestation of emotional pairing at the inter-firm level.

\section{DISCUSSION}

The capabilities-view of M\&As (e.g., Haspeslagh \& Jemison, 1991; Ranft \& Lord, 2002; Zollo \& Singh, 2004) has focused mainly on structural and social processes of integration. Although it is widely acknowledged that M\&As can elicit harmful emotions stemming from cultural issues, there has been insufficient theorizing about how acquirers can deal constructively with these emotions in post-acquisition integration. In response, we have developed an interorganizational, emotion-based model of post-acquisition integration that focuses on the emotional dynamics of integration capability. We discussed how various patterns of harmful emotions could arise based on different integration approaches, and proposed diverse sets of emotional dynamics to foster acquired employees’ organizational identity stabilization, destabilization, and reidentification.

Our model is inter-organizational in that it proposes emotional dynamics that elicit (or 
arouse) certain emotions such as comfort and pride, dissatisfaction, and hope among acquired employees, but also advances other emotions that should be expressed (or conveyed) by the acquirer managers toward acquired employees, such as hubris-containment, empathy, and love. We call the support among emotional dynamics that express emotions and those that elicit other kinds of emotions emotional pairing. Table 3 summarizes its various manifestations.

\section{Insert Table 3 about here}

The concept of emotional pairing extends the emotional capability literature that has focused on intra-organizational strategic change (e.g., Huy, 1999, 2002) with an interorganizational perspective (involving both an acquirer and acquired firm) and by showing how specific emotional dynamics together influence important identification processes during postacquisition integration. In addition, enactment of different sets of organizational actions that deal constructively with emotions can be termed an acquirer's emotional acquisition integration capability (Huy, 1999), which complements other organizational capabilities that have been stressed in previous M\&A research.

\section{Limitations and Directions for Future Research}

While enacting emotional dynamics seems warranted in most types of M\&As, such enactment is not likely to be easy. Various dimensions of individual emotional intelligence, organizational culture, and national culture, to name just three complications, can interact and produce complex situations that make appropriate enactment of various emotional dynamics challenging. In regard to individual emotional intelligence, even if both firms' top executives believe that managing emotions is important to create value in M\&As, they and their middle managers may still have difficulty choosing and enacting diverse emotional dynamics that work to create the 
desired emotional states and behavior with a given group of people in a specific situation (Mayer, Roberts, \& Barsade, 2008). Actions that were intended to express empathy or elicit hope, for example, may instead arouse indifference, cynicism, or anger if recipients of these actions view them as socially awkward, superficial, or manipulative (Huy, 1999).

In this regard, the interactions among various organizational and national cultures inherent to many M\&As promise interesting and important research questions that can explore links between emotions, intercultural interactions, and consequential strategic outcomes. Dealing with emotions reflects an interplay between culture and cognition (Sanchez-Burks \& Lee, 2007). Although there is some degree of universality in non-verbal displays of emotions, enough variation remains to produce culturally unique "accents" in emotional displays that create a handicap at decoding the emotions expressed by people with cultural backgrounds different from those of the perceivers (cf. Elfenbein \& Ambady, 2002). In global and culturally diverse firms that engage in M\&As, cultural differences in emotional display can present a challenge to accurately perceiving the composition of diverse collective emotions in a firm's unit. Implementation challenges are compounded when employees socialized in different national cultures interact. Moreover, the same emotion can produce different behavior in different national cultures. For example, Bagozzi et al. (2003) found that shame experienced in organizational contexts had a negative effect on adaptive behavior and performance among Dutch salespersons, who experienced shame as a threat to the independent self, whereas it had a positive effect on outcomes among Filipinos, who experienced shame as a threat to harmony that needed to be restored. These differences in backgrounds and associated unfamiliarity with cultural expressions of emotions make enactment of emotional dynamics more difficult. For example, Chinese people living in China are less accurate than Chinese people living in the United States at decoding Anglo-American faces. Similar- 
ly, Africans living in the United States are more accurate at decoding African and AngloAmerican faces than at decoding Chinese ones. The good news is that this perceptual inaccuracy can be overcome via training in recognizing emotional expressions and increased exposure to unfamiliar cultures (Elfenbein \& Ambady, 2003).

The current article emphasizes the post-acquisition integration phase, but emotions are obviously not unique to this phase. Another emotionally challenging period may be the phase between announcement and the start of integration. Organizational secrecy typically associated with this phase, however, might constrain the ability of influential members to perform needed emotional dynamics; top managers might not be able to share much information, and middle managers might be less informed about the integration details of the acquisition at this stage. Future research is needed to explore how influential members can manage this stage effectively from an emotional perspective.

Although we have focused on how patterns of emotional experiences and various emotional dynamics can influence identification processes of acquired employees, it is important to consider that other stakeholder groups may also experience M\&As as highly emotional. Customers, for example, might be fearful that products or services will change as a result of the acquisition and choose to go to competitors. Or, suppliers might become nervous about possible contract breaches. Future research can explore how acquirers deal constructively with the emotions of external stakeholders as well as their own employees, not just acquired employees.

With this model, we hope to provide a roadmap for future theorizing and empirical research on emotions in the context of M\&As. Clearly much empirical work is necessary to test the proposed role of emotions. While the study of emotion and emotional dynamics is complex, some works have begun to suggest ways of measuring emotional dynamics (Huy, 1999, 2002). 
Some general assessment of an acquirer's attention to the enactment of emotional dynamics may be measured by the proportion of organizational resources allocated to emotion-managing activities such as budget, specialized support groups, emotion training, or executive time. The overt nature of organizational actions dealing with emotions makes assessment by outsiders and peer observation possible. Beyond overt emotion management actions, the more private emotional states can be studied through self-report accounts and surveys, non-verbal observations, and expressions of such states in support groups or focus groups.

Besides managing the structural-economic aspects of integration, we argue that dealing constructively with acquired employees' emotions is important for realizing economic value. Firm managers often experience M\&As as an intensely personal emotional experience (Graebner \& Eisenhardt, 2004). In reaction to this internal emotional pressure, however, they may not only try to suppress their own emotions, but also may ignore or suppress other firms' employees' emotional experiences, a supposedly rational approach that may prove not so economically rational when one digs more deeply. We hope to have provided a view on acquisition integration that considers treating patterns of emotions as social facts that can help or harm collective action among diverse groups, and that explains how various organizational identification processes unfold as a result of how acquirers deal with the emotions of acquired employees. 


\section{REFERENCES}

Albert, S. 1984. A delete design model for successful transitions. In J. Kimberly, \& R. E. Quinn (Eds.), Managing Organizational Transitions: 169-191. Homewood, IL: Irwin.

Albert, S., \& Whetten, D. A. 1985. Organizational identity. In L. L. Cummings, \& B. M. Staw (Eds.), Research in Organizational Behavior, Vol. 7: 605-617. Greenwich, CT: JAI Press.

Ashforth, B. E. 1998. Becoming: How does the process of identification unfold. In D. A. Whetten, \& P. C. Godfrey (Eds.), Identity in organizations: Developing theory through conversations: 213-222. Thousand Oaks, CA: Sage.

Ashforth, B. E., \& Mael, F. 1989. Social identity theory and the organization. Academy of Management Review, 14(1): 20-39.

Bagozzi, R. P., Verbeke, A., \& Gavino, J. C. 2003. Culture moderates the self-regulation of shame and Its effects on performance: The case of salespersons in the Netherlands and the Philippines. Journal of Applied Psychology, 88(2): 219-233.

Bandura, A. 1997. Self-efficacy: The exercise of control. New York: Freeman.

Bartunek, J. M. 1984. Changing interpretive schemes and organizational restructuring: The example of a religious order. Administrative Science Quarterly, 29: 355-372.

Batson, C. D. 1990. Affect and altruism. In B. S. Moore, \& A. M. Isen (Eds.), Affect and social behavior: 89-125. New York: Cambridge University Press.

Bergh, D. D. 1997. Predicting divestiture of unrelated acquisitions: An integrative model of ex ante conditions. Strategic Management Journal, 18(9): 715-731.

Bougie, R., Pieters, R., \& Zeelenberg, M. 2003. Angry customers don’t come back, they get back: The experience and behavioral implications of anger and dissatisfaction in services. Journal of the Academy of Marketing Science, 31(4): 377-393.

Bower, J. L. 2001. Not all M\&As are alike - And that matters. Harvard Business Review, 79(3): 93-101.

Brewer, M. B., \& Miller, N. E. 1984. Beyond the contact hypothesis: Theoretical perspectivs in desegregation. In N. E. Miller, \& M. B. Brewer (Eds.), Groups in conflict: The psychology of desegregation: 123-146. New York: Academic Press.

Brown, A. D. 1997. Narcissism, Identity, and Legitimacy. Academy of Management Review, 22(3): 643-686.

Buono, A. F., \& Bowditch, J. L. 1989. The human side of mergers and acquisitions: Managing collisions between people, cultures, and organizations. San Francisco: Jossey-Bass Publishers. 
Chatterjee, S., Lubatkin, M. H., Schweiger, D. M., \& Weber, Y. 1992. Cultural differences and shareholder value in related mergers: Linking equity and human capital. Strategic Management Journal, 13(5): 319-334.

Clark, S. M., Gioia, D. A., Ketchen, D. J. J., \& Thomas, J. B. 2010. Transitional identity as a falicitator of organizational identity change during a merger. Administrative Science Quarterly, 55: 397-438.

Cording, M., Christmann, P., \& King, D. R. 2008. Reducing causal ambiguity in acquisition integration: Intermediate goals as mediators of integration decisions and acquisition performance. Academy of Management Journal, 51: 744-767.

Datta, D. K. 1991. Organizational fit and acquisition performance: Effects of post-acquisition integration. Strategic Management Journal, 12(4): 281-297.

Dutton, J. E., Dukerich, J. M., \& Harquail, C. V. 1994. Organizational images and member identification. Administrative Science Quarterly, 39: 239-263.

Dutton, J. E., Worline, M. C., Frost, P. J., \& Lilius, J. 2006. Explaining compassion organizing. Administrative Science Quarterly, 51(1): 59-96.

Edmondson, A. C. 1999. Psychological safety and learning behavior in work teams. Administrative Science Quarterly, 44: 350-383.

Elfenbein, H. A. 2007. Emotion in organization: A review and theoretical integration. Annals of the Academy of Management, 1: 371-457.

Elfenbein, H. A., \& Ambady, N. 2002. On the universality and cultural specificity of emotion recognition: A meta-analysis. Psychological Bulletin, 128(2): 203-235.

Elfenbein, H. A., \& Ambady, N. 2003. Cultural similarity's consequences: A relational perspective on cross-cultural differences in emotion recognition. Journal of Cross Cultural Psychology, 85(2): 276-290.

Ellis, K. M., \& Lamont, B. T. 2004. Ideal acquisition integration strategies in related acquisitions of equals: A test of long-held beliefs. In C. L. Cooper, \& S. Finkelstein (Eds.), Advances in mergers and acquisitions, Vol. 3: 81-102. UK: Elsevier.

Ellis, K. M., Reus, T. H., \& Lamont, B. T. 2009. The effects of procedural and informational justice in the integration of related acquisitions. Strategic Management Journal, 30(2): 137-161.

Empson, L. 2001. Fear of exploitation and fear of contamination: Impediments to knowledge transfer in mergers between professional service firms. Human Relations, 54(7): 839862. 
Empson, L. 2004. Organizational identity change: Managerial regulation and member identification in an accounting firm acquisition. Accounting, Organizations and Society, 29: 759781.

Fiol, C. M. 2002. Capitalizing on paradox: The role of language in transforming organizational identities. Organization Science, 13(6): 653-666.

Gaertner, S. L., Bachman, B. A., Dovidio, J. F., \& Banker, B. S. 2001. Corporate mergers and stepfamily marriages: Identity, harmony, and commitment. In M. A. Hogg, \& D. J. Terry (Eds.), Social identity processes in organizational context. Philadelphia: Psychology Press.

Gioia, D. A., \& Chittipeddi, K. 1991. Sensemaking and sensegiving in strategic change initiation. Strategic Management Journal, 12(6): 433-448.

Graebner, M. E. 2004. Momentum and serendipity: How acquired leaders create value in the integration of technology firms. Strategic Management Journal, 25: 751-777.

Graebner, M. E., \& Eisenhardt, K. M. 2004. The seller's side of the story: Acquisition as courtship and governance as syndicate in entrepreneurial firms. Administrative Science Quarterly, 49(3): 366-403.

Gutierrez, B., Howard-Grenville, J., \& Scully, M. A. 2010. The faithful rise up: split identification and an unlikely change effort. Academy of Management Journal, 53(4): 673-699.

Hambrick, D. C., \& Cannella, A. A., Jr. 1993. Relative standing: A framework for understanding departures of acquired executives. Academy of Management Journal, 36(4): 733-762.

Harquail, C. V. 1998. Organizational identification and the "whole person": Integrating affect, behavior, and cognition. In D. A. Whetten, \& P. C. Godfrey (Eds.), Identities in organizations: Building theory through conversations: 223-231. Thousand Oaks: Sage Publications.

Haspeslagh, P., \& Jemison, D. B. 1991. Managing acquisitions: Creating value through corporate renewal. New York: Free Press.

Hatfield, E., Cacioppo, J. T., \& Rapson, R. L. 1994. Emotional contagion. Cambridge, England: Cambridge University Press.

Hayward, M. L. A., \& Hambrick, D. C. 1997. Explaining the premiums paid for large acquisitions: Evidence of CEO hubris. Administrative Science Quarterly, 42: 103-127.

Hogg, M. A., \& Terry, D. J. 2000. Social identity and self-categorization processes in organizational contexts. Academy of Management Review, 25(1): 121-140.

Huy, Q. N. 1999. Emotional capability, emotional intelligence, and radical change. Academy of Management Review, 24(2): 325-345. 
Huy, Q. N. 2002. Emotional balancing of organizational continuity and radical change: The contribution of middle managers. Administrative Science Quarterly, 47(1): 31-69.

Kahn, W. A. 1990. Psychological conditions of personal engagement and disengagement at work. Academy of Management Journal, 33(4): 692-724.

Kaufmann, G., \& Vosburg, S. K. 1997. "Paradoxical" mood effects on creative problem-solving. Cognition and Emotion, 11: 151-170.

Kim, W. C., \& Mauborgne, R. 1998. Procedural justice, strategic decision making, and the knowledge economy. Strategic Management Journal, 19: 323-338.

King, D. R., Dalton, D. R., Daily, C. M., \& Covin, J. G. 2004. Meta-analyses of post-acquisition performance: Indications of unidentified moderators. Strategic Management Journal, 25(2): 187-200.

Kreiner, G., Hollensbe, E., \& Sheep, M. 2006. Where is the "me” among the "we”? Identity work and the search for optimal balance. Academy of Management Journal, 49: 10311057.

Kusstatscher, V., \& Cooper, C. L. 2005. Managing emotions in mergers and acquisitions. Cheltenham, UK: Edward Elgar Publishing.

Larsson, R., \& Lubatkin, M. 2001. Achieving acculturation in mergers and acquisitions: An international case survey. Human Relations, 54(12): 1573-1607.

Lazarus, R. S. 1991. Progress on a cognitive-motivational-relational theory of emotion. American Psychologist, 46(8): 819-834.

Lerner, J. D., \& Keltner, D. 2001. Fear, anger, and risk. Journal of Personality and Social Psychology, 81: 146-159.

Lewis, M. W. 2000. Exploring paradox: Toward a more comprehensive guide. Academy of Management Review, 25(4): 760-776.

Marks, M. L., \& Mirvis, P. H. 1985. Merger syndrome: Stress and uncertainty. Mergers \& Acquisitions, 20: 50-55.

Mayer, D. M., Roberts, R. D., \& Barsade, S. G. 2008. Human abilities: Emotional intelligence. Annual review of Psychology, 59: 507-536.

Meyer, C. B. 2006. Destructive dynamics of middle management intervention in postmerger processes. The Journal of Applied Behavioral Science, 42(4): 397-419.

Meyer, C. B., \& Altenborg, E. 2007. The disintegrating effects of equality: A study of a failed international merger. British Journal of Management, 18: 257-271. 
Mishra, A. K., \& Spreitzer, G. M. 1998. Explaining how survivors respond to downsizing: The roles of trust empowerment, justice, and work redesign. Academy of Management $\boldsymbol{R e}$ view, 23(3): 567-588.

Nahavandi, A., \& Malekzadeh, A. R. 1988. Acculturation in mergers and acquisitions. Academy of Management Review, 13(1): 79-90.

Napier, N. K. 1988. Mergers and acquisitions, human resource issues and outcomes: A review and suggested typology. Journal of Management Studies, 26(3): 271-290.

Ortony, A., Clore, G. L., \& Collins, A. 1988. The cognitive structure of emotions. New York: Cambridge University Press.

Pratt, M. G. 2000. The good, the bad, and the ambivalent: Managing identification among Amway distributors. Administrative Science Quarterly, 45: 456-493.

Ranft, A. L., \& Lord, M. D. 2002. Acquiring new technologies and capabilities: A grounded model of acquisition implementation. Organization Science, 13(4): 420-441.

Rousseau, D. M. 1998. Why workers still identify with organizations. Journal of Organizational Behavior, 19: 217-233.

Sanchez-Burks, J., \& Huy, Q. N. 2009. Emotional aperture and strategic change: The accurate recognition of collective emotions. Organization Science, 20(1): 22-34.

Sanchez-Burks, J., \& Lee, F. 2007. Culture and workways. In S. Kitayama, \& D. Cohen (Eds.), Handbook of Cultural Psychology, Vol. 1: 346-369. New York: Guilford.

Schweiger, D. M., \& DeNisi, A. S. 1991. Communication with employees following a merger: A longitudinal field experiment. Academy of Management Journal, 34(1): 110-135.

Snyder, C. R., Rand, K. L., \& Sigmon, D. R. 2002. Hope theory: A member of the positive psychology family. In C. R. Snyder, \& S. J. Lopez (Eds.), Handbook of positive psychology: 257-276. New York, NY: Oxford University Press.

Sy, T., Côté, S., \& Saavedra, R. 2005. The contagious leader: Impact of the leader's mood on the mood of group members, group affective tone, and group processes. Journal of Applied Psychology, 90(2): 295-305.

Szulanski, G. 1996. Exploring internal stickiness: Impediments to the transfer of best practice within the firm. Strategic Management Journal, 17: 27-43.

Tajfel, H., \& Turner, J. C. 1979. An integrative theory of social conflict. In W. G. Austin, \& S. Worchel (Eds.), The social psychology of intergroup relations: 33-47. Monterey, CA: Brooks-Cole. 
Terry, D. J., Carey, C. J., \& Callan, V. J. 2001. Employee adjustment to an organizational merger: An intergroup perspective. Personality and Social Psychology Bulletin, 27: 267280.

Ullrich, J., Wieseke, J., \& van Dick, R. 2005. Continuity and change in mergers and acquisitions: A social identity case study of a German industrial merger. Journal of Management Studies, 42(8): 1549 - 1569.

Vaara, E. 2000. Construction of cultural differences in post-merger change processes: A sensemaking perspective on Finnish-Swedish cases. M@n@gement, 3(3): 81-110.

van Knippenberg, D., \& van Leeuwen, E. 2001. Sense of continuity as the key to postmerger identification. In M. A. Hogg, \& D. J. Terry (Eds.), Social Identity Processes in Organizational Contexts: 249-264. Philadelphia, PA: Psychology Press.

van Maanen, J., \& Kunda, G. 1989. Real feelings: Emotional expression and organizational culture. In B. M. Staw, \& I. Cummings (Eds.), Research in Organizational Behavior, Vol. 11: 43-103. Greenwich, CT: JAI Press.

Weiss, H. M., \& Cropanzano, R. 1996. Affective events theory: A theoretical discussion of the structure, causes and consequences of affective experiences at work. Research on Organizational Behavior, 18(1): 1-74.

Winnicot, D. W. 1965. The maturational process and the facilitating environment. London: The Hogarth Press.

Zollo, M., \& Singh, H. 2004. Deliberate learning in corporate acquisitions: Post-acquisition strategies and integration capability in U.S. bank mergers. Strategic Management Journal, 25(13): 1233-1257. 
FIGURE 1

EMOTIONAL DYNAMICS OF INTEGRATION CAPABILITY

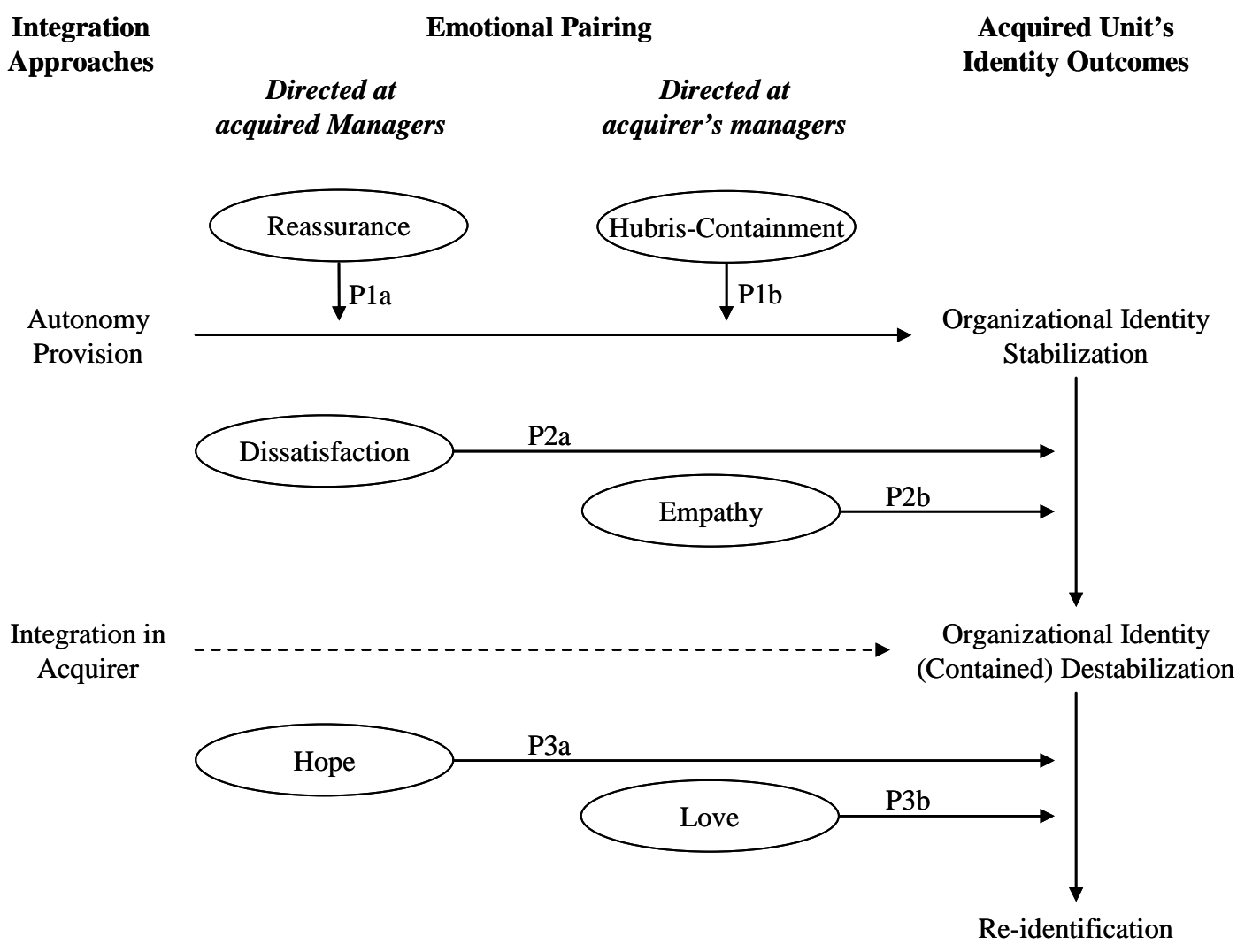




\begin{tabular}{|c|c|c|c|c|c|c|c|}
\hline Approach & Common motives & $\begin{array}{l}\text { Boundary } \\
\text { goals }\end{array}$ & $\begin{array}{l}\text { Culture } \\
\text { goals }\end{array}$ & $\begin{array}{l}\text { Managing } \\
\text { Top teams }\end{array}$ & $\begin{array}{l}\text { Power } \\
\text { dynamics }\end{array}$ & $\begin{array}{l}\text { Managing } \\
\text { middle mgmt. }\end{array}$ & $\begin{array}{l}\text { Key identification } \\
\text { processes }\end{array}$ \\
\hline $\begin{array}{l}\text { Autonomy } \\
\text { provision }\end{array}$ & $\begin{array}{l}\text { Strategic: } \\
\text { Extending into new mar- } \\
\text { ket; Exploring, nurturing } \\
\text { acquired capabilities } \\
\text { Operational: } \\
\text { Maintaining acquired } \\
\text { members’ commitment to } \\
\text { acquired capabilities }\end{array}$ & $\begin{array}{l}\text { Boundary } \\
\text { protection }\end{array}$ & $\begin{array}{l}\text { Keep acquired } \\
\text { firm’s culture } \\
\text { intact }\end{array}$ & $\begin{array}{l}\text { Retain ac- } \\
\text { quired top } \\
\text { management }\end{array}$ & $\begin{array}{l}\text { Acquired top } \\
\text { managers re- } \\
\text { tain control } \\
\text { over acquired } \\
\text { unit; Conflicts } \\
\text { arise when } \\
\text { boundary is in } \\
\text { jeopardy }\end{array}$ & $\begin{array}{l}\text { Acquired middle } \\
\text { management } \\
\text { retains autonomy } \\
\text { steered by ac- } \\
\text { quired top man- } \\
\text { agement }\end{array}$ & $\begin{array}{l}\text { Stabilization of organi- } \\
\text { zational identity }\end{array}$ \\
\hline Integration & $\begin{array}{l}\text { Strategic: } \\
\text { Building market position } \\
\text { quickly; Optimizing cost } \\
\text { efficiency; Exploiting } \\
\text { existing capabilities of } \\
\text { acquirer } \\
\text { Operational: } \\
\text { Fostering acquired mem- } \\
\text { bers' commitment to ac- } \\
\text { quirer’s capabilities }\end{array}$ & $\begin{array}{l}\text { Boundary } \\
\text { dissolution }\end{array}$ & $\begin{array}{l}\text { Assimilate } \\
\text { acquired } \\
\text { members in } \\
\text { acquirer's cul- } \\
\text { ture }\end{array}$ & $\begin{array}{l}\text { Bring ac- } \\
\text { quired top } \\
\text { managers } \\
\text { into the fold } \\
\text { of acquirer, } \\
\text { or let them } \\
\text { go }\end{array}$ & $\begin{array}{l}\text { Acquirer's } \\
\text { managers take } \\
\text { control of } \\
\text { weaker ac- } \\
\text { quired unit }\end{array}$ & $\begin{array}{l}\text { Bring acquired } \\
\text { middle manage- } \\
\text { ment into the } \\
\text { fold }\end{array}$ & $\begin{array}{l}\text { Destabilization of or- } \\
\text { ganizational identity } \\
\text { Re-identification }\end{array}$ \\
\hline
\end{tabular}


Table 2: Potentially Harmful Emotions and Behavioral Outcomes during Post-Acquisition Integration

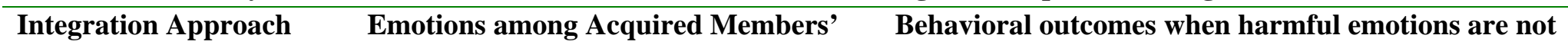
addressed

Autonomy provision

Integration

Vigilance; constrained in sharing full knowledge to acquirer because of acquired firm's fear of future appropriation

Exit; detachment; non-cooperation; sabotage; low creativity and initiative-taking in acquired firm

Widespread fear, anger, sadness associated with loss of identity and status, exploitation, in-group favoritism; Unresolved pride about, and attachment to, old company; Survivor guilt 


\begin{tabular}{|c|c|c|c|c|}
\hline Dynamic & Definition & $\begin{array}{l}\text { Principal } \\
\text { target }\end{array}$ & $\begin{array}{l}\text { Illustrative organizational } \\
\text { action }\end{array}$ & $\begin{array}{l}\text { Illustrative } \\
\text { literature }\end{array}$ \\
\hline \multicolumn{5}{|c|}{ Emotional Pairing for Organizational Identity Stabilization } \\
\hline Reassurance & $\begin{array}{l}\text { Evoking emotions of pride and } \\
\text { comfort in regard to managing the } \\
\text { acquired firm quasi-autonomously }\end{array}$ & $\begin{array}{l}\text { Acquired } \\
\text { executives }\end{array}$ & $\begin{array}{l}\text { Reminding that acquirer respects } \\
\text { distinct competences of acquired } \\
\text { firm }\end{array}$ & (Edmondson, 1999) \\
\hline Hubris-Containment & $\begin{array}{l}\text { Limiting expression of display of } \\
\text { excessive pride about one’s own } \\
\text { attributes }\end{array}$ & $\begin{array}{l}\text { Acquirer's } \\
\text { managers }\end{array}$ & $\begin{array}{l}\text { Avoiding to make comparison } \\
\text { statements that risk creating feel- } \\
\text { ings of shame }\end{array}$ & (Brown, 1997) \\
\hline \multicolumn{5}{|c|}{ Emotional Pairing for (Contained) Organizational Identity Destabilization } \\
\hline Dissatisfaction & $\begin{array}{l}\text { Evoking distress emotions that } \\
\text { people's goals or needs are not } \\
\text { met }\end{array}$ & $\begin{array}{l}\text { Acquired } \\
\text { managers }\end{array}$ & $\begin{array}{l}\text { Helping to see prior ways of } \\
\text { doing are no longer optimal for } \\
\text { the firm's long-term welfare }\end{array}$ & (Ortony et al., 1988) \\
\hline Empathy & $\begin{array}{l}\text { Expressing emotion of feelings of } \\
\text { sympathy and concern for the } \\
\text { other }\end{array}$ & $\begin{array}{l}\text { Acquirer's } \\
\text { managers }\end{array}$ & $\begin{array}{l}\text { Training acquirer's managers so } \\
\text { that they can feel what acquired } \\
\text { employees go through }\end{array}$ & (Dutton et al., 2006) \\
\hline \multicolumn{5}{|c|}{ Emotional Pairing for Re-identification } \\
\hline Hope & $\begin{array}{l}\text { Evoking emotions of anticipated, } \\
\text { better collective future in the } \\
\text { combined firm }\end{array}$ & $\begin{array}{l}\text { Acquired } \\
\text { managers }\end{array}$ & $\begin{array}{l}\text { Energizing participation in im- } \\
\text { proving the collective welfare of } \\
\text { the firm }\end{array}$ & (Snyder, 1994) \\
\hline Love & $\begin{array}{l}\text { Expressing emotion of attachment } \\
\text { to acquired employees }\end{array}$ & $\begin{array}{l}\text { Acquirer's } \\
\text { managers }\end{array}$ & $\begin{array}{l}\text { Providing favorable access to } \\
\text { influential positions in the new } \\
\text { firm }\end{array}$ & $\begin{array}{l}\text { (Van Maanen \& } \\
\text { Kunda, 1989) }\end{array}$ \\
\hline
\end{tabular}

